\title{
Quando o Reuni aderiu à universidade
}

\author{
José Renato Bez de Gregório* \\ Viviane de Souza Rodrigues*
}

Deise Mancebo ${ }^{* * *}$

\section{Resumo}

O presente artigo busca analisar como as recentes reconfiguraçôes das universidades federais (IFES) no País têm sido processadas de forma compartilhada entre o governo federal, através do Ministério da Educação (MEC), reitores e setores importantes destas instituições. Apresenta conclusōes a partir da análise das mudanças políticopedagógicas engendradas, no início da primeira década deste novo século, pelas universidades no contexto de sua inserção na contrarreforma da Educação Superior. Através da análise de documentos institucionais das universidades pesquisadas, particularmente da Universidade Federal Fluminense (UFF), o texto aponta as diretrizes que orientam tais alteraçóes e conclui que o recente Programa de Apoio aos Planos de Reestruturação e Expansão das Universidades Federais (Reuni) cumpriu, em grande medida, o papel de ampliar e legitimar um processo de reforma das IFES, já em curso antes de sua implementação.

Palavras-chave: Política da educação. Educação Superior. Reforma universitária.

\footnotetext{
* Mestre em Educação pela Universidade Federal Fluminense - UFF. Servidor TécnicoAdministrativo na mesma Universidade.

** Doutoranda em Educação pela Universidade Federal Fluminense - UFF. Servidor TécnicoAdministrativo na mesma Universidade.

*** Doutora em Educação pela Pontifícia Universidade Católica de São Paulo - PUC/SP. Professora Titular da Universidade Estadual do Rio de Janeiro - UERJ.
} 


\section{Introdução}

Este artigo apresenta alguns resultados de pesquisa que trata das "Políticas de expansão da Educação Superior no Brasil". ${ }^{1}$ O texto expóe, primeiramente e em traços bem gerais, os fundamentos do processo de contrarreforma ${ }^{2}$ da Educação Superior em curso no Brasil, sobretudo as alteraçôes operacionalizadas nas universidades federais, no governo de Luís Inácio Lula da Silva. Nesta parte do texto, a análise teve por base a consulta aos Planos de Desenvolvimento Institucional (PDI) de algumas instituiçóes, antes da criação do Programa de Apoio aos Planos de Reestruturação e Expansão das Universidades Federais (Reuni) em 2007.

$\mathrm{Na}$ segunda parte, são apreciados, mais detidamente, os documentos institucionais da Universidade Federal Fluminense - UFF, com o intuito de exemplificar de que maneira uma série de alteraçóes político-pedagógicas já estavam em curso nesta instituição antes de sua adesão ao Reuni.

Por fim, salientamos que as diretrizes preconizadas pelo Reuni são, em grande medida, expressão das açóes anteriormente praticadas em muitas universidades federais do País e, portanto, que o processo de reconfiguração da Educação Superior pública tem ocorrido de forma compartilhada entre governo federal, através do Ministério da Educação (MEC), reitores e importantes setores das universidades.

\section{A contrarreforma da Educação Superior no Brasil}

Partimos do pressuposto de que as políticas governamentais para a Educação Superior se orientam pelos princípios da Reforma do Estado no Brasil, em curso desde 1995, e pela reconfiguração da economia nacional de acordo com a mundializaçáo e a financeirização do capital. A inserçáo capitalista dependente do Brasil no cenário internacional reflete-se no campo educacional, particularmente no que tange às ideias e açóes compartilhadas entre governo federal e organismos internacionais, o que tem transformado, progressivamente, a universidade pública brasileira em instituiçáo calcada na lógica da "educaçáo terciária”, amplamente defendida e difundida pelo Banco Mundial (BANCO MUNDIAL, 2003).

Nesta adesão, nem sempre explicitada, é que a contrarreforma da Educação Superior no governo de Luís Inácio Lula da Silva aprofundou alguns 
fundamentos e diretrizes já delineados no governo anterior, e que têm deixado profundas marcas no sistema de Educação Superior, como: a diversificação das instituições de Ensino Superior, dos cursos e do financiamento e, o que é mais grave, a noção da educação como "bem público", cujas concepções vêm interferindo no desenvolvimento, expansão e avaliação da Educação Superior do País (LIMA, 2007). A concepção da educação como um "bem público", e não como um direito, merece especial atenção, pois forneceu as bases jurídicas e políticas para que se borrassem as diferenças entre público e privado, admitindo, explicitamente, a possibilidade de financiamento das Instituiçôes de Educação Superior (IES), independente de sua organização acadêmica (IES públicas ou privadas), por fontes públicas ou privadas. Sendo assim, instituiçôes privadas passaram a ser financiadas mais agressivamente pelo fundo público, especialmente através da ampliação da renúncia fiscal, e, por outro lado, instituiçóes públicas têm sido instadas a captar, progressivamente, o financiamento privado para atividades de ensino, pesquisa e extensão, como é o caso das tăo incentivadas parcerias público-privadas.

Deve-se relevar que o empresariamento da Educação Superior (NEVES, 2002) foi iniciado de maneira tímida no governo Collor-Itamar, implementado no governo de Fernando Henrique Cardoso (FHC) e aprofundado sob a presidência de Luís Inácio Lula da Silva, sob duas frentes: 1) mediante a adoção de novos programas que possibilitaram a ampliaçáo do número de cursos privados - ao final do governo FHC, as IES privadas detinham 69,7\% das matrículas e, em 2010, ao final do governo Lula, o percentual subiu para 74,1\%, conforme dados do Censo da Educação Superior (BRASIL, 2002, 2010) - e 2) mediante a privatizaçẫo interna das instituiçôes públicas.

Como a privatizaçáo das universidades e a submissão da produçáo e formação acadêmicas à configuração atual do capitalismo náo poderiam ser realizadas, de um só golpe, por meio de alteraçóes constitucionais, a contrarreforma da Educaçấo Superior no Brasil ocorre a "conta gotas", a partir de um conjunto de leis, decretos e medidas provisórias, como: 1) a criação em 2003, por decreto, do Grupo de Trabalho Interministerial (GTI) para analisar a situação da Educação Superior brasileira e apresentar um plano de ação para a reestruturação e expansão das Instituiçóes Federais de Ensino Superior (IFES); 2) a PEC 217/2003, que versava sobre as fontes de financiamento das universidades; 3) o projeto de Lei Complementar no 118/2003 sobre a Lei Orgânica da Autonomia Universitária; 4) a Lei no 10.861/2004, que instituiu 
o Sistema Nacional de Avaliação do Ensino Superior (Sinaes); 5) a Lei no 11.096/2005, que criou o Programa Universidade para Todos (ProUni), com a proposta de oferecer a alunos de baixa renda bolsas de estudo em faculdades privadas, concedendo a essas isenção de alguns tributos fiscais; 6) a Lei no 10.973/2004, de Inovação Tecnológica, que versa sobre o estabelecimento de parcerias entre universidades públicas e empresas; 7) o Projeto de Lei no 3.627/2004, que cria o Sistema Especial de Reserva de Vagas; 8) a Lei no 11.079/2004 com o Projeto de Parceria Público-Privada (PPP), que abrange um vasto conjunto de atividades governamentais; 9) o Decreto no ${ }^{\mathbf{5}}$.205/2004, que regulamenta as parcerias entre as universidades federais e as fundaçóes de direito privado; 10) o Projeto de Lei no 7.200/2006, que trata da Reforma da Educaçâo Superior e se encontra no Congresso Nacional; 11) o Decreto no 5.800/2006, que instituiu o sistema Universidade Aberta do Brasil (UAB); 12) o Decreto de no 6.096/2007, que criou o Programa de Apoio a Planos de Reestruturação e Expansão das Universidades Federais (Reuni); 13) a Portaria Interministerial nº 22 MEC/MP de 2007, que instituiu o "banco de professoresequivalentes" em consonância com a política do Reuni; 14) a Medida Provisória no 435/2010, que busca legalizar as relaçóes já existentes na universidade com as fundaçôes de apoio; 15) o Decreto no 7.232/2010, que instituiu um mecanismo de gerenciamento do quadro dos servidores técnico-administrativos estabelecendo a possibilidade de as IFES reporem as vacâncias existentes no seu quadro sob fiscalização do MEC; 16) o Decreto nํㅜ.233/2010, que trata sobre a desobrigação de recolhimento dos recursos financeiros das IFES ao final de cada exercício pelo Tesouro Nacional; 17) o Decreto no 7.234/2010, que cria o Programa Nacional de Assistência Estudantil (Pnaes); e 18) o Projeto de Lei no 1.749 , que autoriza a criaçáo de uma empresa pública de direito privado, chamada de empresa Brasileira de Serviços Hospitalares, destinada à prestaçáo de serviços à saúde e ao apoio administrativo dos hospitais universitários.

Esta extensa citação sobre a regulamentação recente da Educação Superior no País indica a construção de uma nova cultura institucional que remete, no conjunto, à ampliação dos espaços par a atuaçáo dos empresários da educação e, por outro, à privatização interna das instituiçóes públicas.

Na impossibilidade de abordarmos o conjunto das medidas, analisaremos neste texto tão-somente os reflexos e precedentes institucionais do Programa de Apoio a Planos de Reestruturação e Expansão das Universidades Federais (Reuni) em algumas universidades. 
Nesta análise, deparamo-nos, preliminarmente, com uma situação no mínimo intrigante: os Planos de Desenvolvimento Institucional (PDIs) de algumas universidades, como os da UFF (2004), Universidade Federal do Rio de Janeiro - UFRJ (2006), Universidade Tecnológica Federal do Paraná - UTFPR (2006), Universidade Federal de São Paulo - Unifesp (2005), Universidade Feral de Mato Grosso do Sul - UFMS (2005), todos elaborados antes de 2007 (ano do Decreto de no 6.096/2007, que estabeleceu o Reuni), já apresentavam os pilares básicos do Reuni e outros arcabouços jurídicos que fundamentam a contrarreforma da Educação Superior.

Em linhas gerais, os PDIs analisados convergem em aspectos estratégicos abaixo relacionados, muitos dos quais presentes no Programa Reuni:

- aumento do número de vagas na graduação;

- ampliação das bolsas estudantis;

- uso de novas tecnologias no processo de ensino-aprendizagem;

- elevação do conceito Capes nos programas e pós-graduação sctrito-sensu existentes;

- fomento à criação de novos programas, consolidação e expansão dos cursos de pós-graduação lato-sensu;

" desenvolvimento de "pesquisas inovadoras" que atendam aos interesses da "sociedade";

- disponibilização de acesso aos recursos da informática, internet e novas tecnologias aos alunos;

- promoção de mobilidade acadêmica interinstitucional, pela transferência de estudantes de outras universidades;

- ampliação da mobilidade interna de estudantes nos diversos cursos;

- aumento do número de cursos e matrículas de pós-graduação strictosensu;

- ampliação de recursos obtidos através de editais de fomento;

- elevação do número de projetos inovadores e patentes;

- ampliação dos programas de assistência estudantil na perspectiva da inclusão social.

Esta breve constatação nos permite questionar a tese de que o Reuni partiu exclusivamente do MEC e de que este foi imposto às universidades 
federais. Ao contrário, confirma-se a hipótese de que a contrarreforma da Educação Superior no Brasil é um conjunto de açốes compartilhadas entre governo federal e parcelas importantes da comunidade universitária, através de iniciativas e interesses entrelaçados, que passaremos a analisar mais detidamente na Universidade Federal Fluminense.

\section{Analisando o caso da UFF}

$\mathrm{Na}$ Universidade Federal Fluminense - UFF, o processo de contrarreforma da Educação Superior também se encontrava em curso, quando da emissão do Decreto que estabeleceu o Reuni, em 2007, ao qual esta aderiu de maneira bastante controversa.

Um primeiro projeto de adesão ao Reuni foi elaborado por um grupo restrito e vinculado à reitoria da Universidade. Depois de uma série de protestos organizados pelos estudantes e pelas entidades sindicais representativas dos docentes e dos técnico-administrativos, uma reuniáo do Conselho Universitário foi marcada para decidir que a "[...] UFF não iria aderir ao Reuni e elaboraria um projeto próprio de expansão, autônomo, a partir do trabalho de uma comissão de representantes do conselho universitário" (MATTOS, 2009, p. 198).

Esta indicação dos representantes do Diretório Central dos Estudantes (DCE) não foi aceita, e, em contrapartida, foi proposta a realização de um "novo projeto autônomo" de expansão que, na realidade, quando apresentado, revelou ter o mesmo conteúdo do projeto apresentado originalmente, suprimindo-se apenas a palavra Reuni. Após algumas reuniôes sem sucesso, troca de empurrôes e cenas lamentáveis, a adesão da UFF ao Reuni foi aprovada no Palácio da Justiça de Niterói, sob forte escolta policial, onde estudantes e sindicalistas foram impedidos de participar (MATTOS, 2009). Mesmo diante dos tristes fatos ocorridos, o desfecho foi comemorado pela administraçáo central, baseados na retórica de que a Universidade, com a adesão, conseguiria "fartos recursos".

Todavia, o Reuni, como todos os mecanismos atrelados a ele na composição da contrarreforma universitária posta em prática pelo governo Luís Inácio Lula da Silva (2003-2010), não nasceu na UFF, naquela sala cedida pelo Poder Judiciário. Sua gênese pode ser localizada em diversas açóes desenvolvidas no interior da UFF desde a administraçáo anterior, através de documentos que analisaremos em seguida, como: 1) o Projeto Pedagógico-Institucional (PPI) da UFF; 2) o Plano de Desenvolvimento Institucional (PDI) da UFF; 3) o 
Projeto de Adesão da UFF ao Programa Reuni; 4) o Regulamento dos Cursos de Graduação; 5) o segundo Plano de Desenvolvimento Institucional (PDI); e 6) o Termo de Acordo de Metas celebrado entre a UFF e o MEC (ADUFF, 2008).

\section{Projeto Pedagógico-Institucional (PPI) - 2002}

Em junho de 2002, a Comissão de Redação instituída pela Portaria GAR no 29.393, de 26/10/2001 (UFF, 2001), divulgou o documento "Projeto Pedagógico-Institucional da UFF", aprovado pelo Conselho de Ensino e Pesquisa (CEP), através da Decisão nº 495/2002. O documento afirmava reiteradas vezes o compromisso da UFF com os princípios da autonomia, liberdade de ensino e pluralidade de práticas pedagógicas, além de defender a produção de conhecimento e a formação de profissionais capacitados para o mercado.

O Projeto Pedagógico faz, ainda, uma defesa contundente do enfoque interdisciplinar que, segundo o documento, promoverá a:

[...] superaçáo da visão restrita de mundo e a compreensão da complexidade da realidade, pois ele pressupóe uma atitude de abertura náo preconceituosa onde todo o conhecimento é igualmente importante, onde o conhecimento individual esvazia-se frente ao conhecimento universal. (UFF, 2002, p. 17).

A defesa da implantação do modelo transdisciplinar nos cursos da UFF tem continuidade em outras partes do texto, pautada no argumento da "unidade do conhecimento" e na "compreensão do mundo atual", ressaltando o "[...] espírito de parceria e de integração entre teoria e prática, conteúdo e realidade, objetividade e subjetividade, ensino e avaliação, meios e fim, tempo e espaço, professor e aluno, reflexo e ação" (UFF, 2002, p. 17).

Há grande ênfase, ainda, numa formação que conduza o estudante a "[...] aprender a ser, a fazer, a viver junto e a conhecer" (UFF, 2002, p. 18), mal disfarçando a influência do pensamento da Organização das Nações Unidas para a Educação, Ciência e Cultura (UNESCO, 1998), na Conferência Mundial sobre o Ensino Superior em 1998, em Paris.

Além disso, o PPI/UFF sinaliza a necessidade de se "[...] educar para a paz e para a compreensão entre todos os seres humanos" (UFF, 2002, p. 20) 
e defende a aplicação de "[...] metodologias que valorizem as experiências de auto-aprendizagem” (UFF, 2002, p. 21).

A UFF, segundo o PPI, deveria estimular a criatividade, combinando o saber tradicional com as novas tecnologias da informação, transformar os cursos de graduação em etapas de um processo de educação continuada, assim como incentivar e promover cursos sequenciais, e implantar cursos a distância e semipresenciais. Aponta, por fim, para a necessidade de atividades que integrem a pesquisa, o estágio, a monitoria e projetos de apoio social aos estudantes.

A despeito de belos princípios que, aqui e acolá, podem ser colhidos no documento, uma observaçáo mais atenta permite detectar que, em diversas oportunidades, o PPI, com o fito de ultrapassar o paradigma da disciplinaridade, indica o direcionamento do projeto pedagógico para um modelo voltado para a "flexibilização das estruturas curriculares" (UFF, 2002, p. 18). A semelhança com o modelo interdisciplinar e/ou transdisciplinar, que mais tarde seria uma das bases dos cursos de bacharelado interdisciplinar (BI), do programa Reuni é bastante grande (UFF, 2002).

Como veremos adiante, nos demais documentos analisados, a concepção de ensino, pesquisa e extensão no bojo dessa reestruturação "transdisciplinar" e "flexível", na verdade, comparece para atender a interesses privados, com a flexibilizaçáo de regras e a abertura de espaços para projetos de pesquisa, consultorias e prestação de serviços para empresas, no mesmo compasso em que se inicia a massificação da formação profissional.

\section{Primeiro Plano de Desenvolvimento Institucional (PDI) - 2003-2007}

O primeiro Plano de Desenvolvimento Institucional (PDI), referente ao quadriênio 2003-2007, foi aprovado pelos Conselhos Superiores da UFF em 2004. A sua elaboração partiu dos pressupostos e demandas sinalizados pelo PPI para estabelecer mecanismos para o desenvolvimento da Universidade.

Como o PPI, este documento destaca as "constantes mudanças" que acontecem num "[...] mundo marcado pelo paradigma da pós-modernidade, pelo desgaste das utopias, o progressivo desenvolvimento e disseminação das novas tecnologias de comunicação e descentralização do conhecimento" (UFF, 2004, p. 10), demonstrando uma forte conformidade com os paradigmas dos 
organismos internacionais do capital para os países do capitalismo periférico. O PDI 2003-2007 (UFF, 2004) aponta a expansão da graduação, da pósgraduação e da extensão como rumo a ser seguido pela UFF, destacando também a necessidade de diversificar suas fontes de recursos financeiros, maior interação com a sociedade e a implantação de currículos interdisciplinares em seus cursos.

Vale destacar, entre as açóes estratégicas apontadas pelo PDI 2003-2007 (UFF, 2004), o combate à evasão estudantil, a redução da retenção dos alunos, a criação de cursos noturnos, a implantação de novos cursos de graduação, principalmente de caráter interdisciplinar, e a implementaçáo do Núcleo de Educação Assistida por Meios Interativos (NEAMI).

Conforme analisa Lima (2009, p. 7):

Se estas propostas já estavam presentes nos dois documentos fundamentais da política pedagógica da UFF e já eram, portanto, prioridades institucionais, com a divulgação, em 2007, do Decreto de criação do Reuni, elas seráo consideradas como eixos centrais da reformulaçáo político-pedagógica em curso na universidade.

Em síntese, os instrumentos legais elaborados no interior da UFF já se encontravam em conformidade com as diretrizes do Decreto que instituiu o Reuni, e, em consequência, os defensores do projeto governamental encontraram um caminho bastante pavimentado para disseminar suas ideias nas instâncias que decidiriam o futuro da Universidade.

\section{Projeto de Adesão ao Reuni - 2007}

O Projeto da UFF para adesão ao Reuni foi aprovado pelo Conselho Universitário em novembro de 2007, na já citada reunião ocorrida no Palácio da Justiça. O documento aprovado apresentava-se dividido em cinco dimensões - 1) Ampliação da Oferta de Educação Superior Pública; 2) Reestruturação Acadêmico-Curricular; 3) Renovaçâo Pedagógica da Educação Superior; 4) Mobilidade Intra e Interinstitucional; e 5) Compromisso Social da Instituição e Suporte da pós-graduação ao desenvolvimento e aperfeiçoamento qualitativo dos cursos de graduação - articuladas entre si e que, muitas vezes, se repetiam ou se sobrepunham. 
O documento considera que a realização de concursos públicos para docentes e técnico-administrativos estará, assim como a distribuição de novas gratificaçôes para cargos comissionados, condicionada à assinatura de um termo de metas entre a UFF e o MEC, e apresenta, em geral, medidas para o incremento da estrutura física da Universidade (reformas e construçóes de novos prédios), além de definir medidas para a assistência estudantil e a concessão de bolsas para alunos.

Outros aspectos ressaltados são o combate à evasão e a reposição das vagas ociosas pela proposição de oferta de bolsas de monitoria on-line, pela implementação de EAD, de cursos de férias semipresenciais, assim como a articulação de discentes da pós-graduação com alunos da graduação. Prevê a criação de novos cursos ou turnos no horário noturno - pelo menos, 25 novos cursos de graduação, preferencialmente nos polos do interior do Estado - o aumento do número de matrículas na sede e a elevação da relaçáo professor/aluno, a fim de satisfazer as metas estabelecidas pelo Decreto do Reuni.

O aligeiramento da formação profissional transparece no documento, em trechos como: "[...] cada aluno [deve poder] cursar suas disciplinas/ atividades no menor número possível de turnos e [deve-se criar] mecanismos de aprofundamento e aceleração de estudos para os bons alunos" (UFF, 2007, p. 23). Há forte defesa de currículos mais flexíveis, com menos disciplinas obrigatórias e mais optativas, para que o aluno direcione a sua formação. O Projeto da Adesão (UFF, 2007) não menciona, em momento algum, os bacharelados interdisciplinares (BIs) e os ciclos básicos ${ }^{3}$, nem defende explicitamente a "diversificação das modalidades de graduação". Todavia, conforme Lima (2009, p. 8):

[...] "espalha" essa lógica de fragmentação e aligeiramento no conjunto das estratégias de reorganização acadêmica e no item específico, [que trata] da "Diversificação das modalidades de graduaçâo", avalia que existem cursos da universidade com configuraçáo mais flexível e multidisciplinar que poderão funcionar através da oferta de disciplinas obrigatórias comuns, o que significa, na prática, a implantação dos ciclos/BIs em alguns cursos de graduação considerados mais "flexíveis". 
Deve-se destacar, ainda, o item "Implantação de regimes curriculares e de um novo sistema de títulos" (UFF, 2007), que apresentava explicitamente a possibilidade de certificação ao longo do itinerário formativo e da emissão de diplomas parciais, conforme o aluno for completando seu itinerário.

Por fim, com relação ao projeto político-pedagógico, a Adesão sustentouse em três pilares para uma reformulação e expansão da UFF: uso das novas tecnologias da informação e comunicação, inserção de alunos na docência e mobilidade estudantil. Em síntese, foi de fato uma Adesão orgânica aos modelos apresentados pelo Decreto do Reuni!

\section{Regulamento dos Cursos de Graduação - 2008}

O Regulamento dos Cursos de Graduaçáo da UFF (UFF, 2008), aprovado pelo Conselho de Ensino e Pesquisa da Universidade, é outro importante documento para análise, pois apresenta um arcabouço normativo que tem sustentado a operacionalização das alteraçóes acadêmico-curriculares do Reuni na UFF, oriundas de uma série de reuniôes realizadas pelo Fórum de Coordenadores dos Cursos de Graduação e conduzidas pela Pró-Reitoria de Assuntos Acadêmicos.

O regulamento, primeiramente, trata das formas de ingresso na Universidade, que são por vestibular, transferência, reingresso, mudança de curso, rematrícula, revinculação e convênio cultural. Entre as alterações nas formas de ingresso, chama-nos a atenção a possibilidade de realizaçáo de vestibular, de uma só vez, para um conjunto de cursos de graduação que adotem a estrutura de um primeiro ciclo básico comum e um segundo ciclo de profissionalização. Vejamos o que diz um dos parágrafos do artigo 3:

$\$ 2^{\circ}$ - Poderá ser aceita inscrição no Vestibular para um grupo de Cursos de Graduação com ciclo básico comum, desde que haja a concordância dos Colegiados dos mesmos, sendo que, completado o ciclo básico, o aluno terá vaga garantida em um deles, sendo as preferências dos alunos atendidas conforme a existência de vagas nos Cursos e o desempenho dos alunos nas disciplinas do ciclo básico, de acordo com regras definidas em comum pelos Cursos envolvidos. (UFF, 2008, p. 10). 
Em síntese, por caminhos tortuosos, está admitido o ciclo básico. A sessão do regulamento que merece maior destaque, no entanto, referese às "Normas e Procedimentos Acadêmicos" (UFF, 2008), porque em seu bojo modificaçôes significativas são introduzidas, que podem alterar profundamente a estrutura e a formação oferecida pelos cursos de graduação da UFF. A primeira delas encontra-se no Capítulo 1 do Regulamento e versa sobre a criação de cursos de graduação, facultando mudanças nos currículos novos, antes mesmo de sua integralização, para flexibilizaçáo curricular em prol da redução do tempo de permanência do aluno e para adequação do currículo às diretrizes do PPI (UFF, 2002) e do PDI (UFF, 2004). Trata-se de uma diretriz central - ademais, também presente nos documentos anteriormente analisados - em prol da flexibilização e do aligeiramento da formação. Tal ordenamento ainda se apresenta sob outras formas, como, por exemplo, no Capítulo 5 (UFF, 2008), quando trata das "Atividades e Disciplinas", onde se pode observar o destaque ao uso do ensino a distância em até $20 \%$ da carga horária do ensino presencial através do Núcleo de Educação Assistida por Meios Interativos (NEAMI). O parágrafo abaixo, transcrito do artigo 35 , mostra que o objetivo deste mecanismo nada mais é do que acelerar a formação: " $\$ 6^{\circ}-$ As disciplinas às quais se refere o $\$ 5^{\circ}$, supra, poderão ser utilizadas pelos Cursos com os seguintes objetivos: Nivelamento de estudos; Aproveitamento de estudos; Aceleração de estudos; Reforço de ensino; e Apoio didático a disciplinas do curso". (UFF, 2008, p. 22).

A flexibilização e a aceleração dos cursos também se fazem presentes no Capítulo 5 (UFF, 2008), na parte referente às "Atividades Complementares", onde se torna obrigatório, para todos os cursos de graduação da UFF, o aproveitamento da participaçáo do aluno em seminários, debates, projetos de monitoria. $\mathrm{O}$ artigo 39 as define como:

Art. 39 - Entendem-se como Atividades Complementares (AC) as atividades que possibilitam o reconhecimento de habilidades, conhecimentos e competências do aluno, inclusive adquiridas fora do ambiente escolar, que estimulem a prática de estudos independentes e opcionais, permitindo a permanente e contextualizada atualização profissional específica como complementação de estudos. (UFF, 2008, p. 24). 
Outro elemento novo do Regulamento, que também remete à flexibilização da formação do aluno, é a "Mobilidade Acadêmica" (UFF, 2008), pois faculta ao aluno de graduação cursar componentes curriculares em outras IFES que tenham convênio com a UFF, durante um ano.

Por fim, no mesmo Capítulo 5 (UFF, 2008), no item referente ao "Aproveitamento de Estudos", que de certo modo sintetiza as alteraçóes acadêmico-curriculares trazidas pelos demais documentos da Universidade e já analisados anteriormente, encontra-se a possibilidade do aproveitamento de estudos através dos mecanismos de dispensa de disciplinas/atividades, da equivalência de disciplinas/atividades, dos estudos/disciplinas semipresenciais através da PROAC/NEAMI, do exame de proficiência e da mobilidade acadêmica.

Em suma, como destaca Lima $(2009,154)$ :

Da análise do referido documento, destacamos a reflexão sobre o significado da reformulação político-pedagógica que está sendo realizada na UFF e que indica, na configuração do "novo" Regulamento dos Cursos de Graduação, a possibilidade de que $20 \%$ das disciplinas sejam cursadas a distância, $20 \%$ da carga horária das disciplinas seja cursada em outra IES, pública ou privada, brasileira ou estrangeira e que $40 \%$ da carga horária total do curso possa ser dispensada pelo Exame de Proficiência.

O aluno que fizer uso de todas essas possibilidades, de fato, concluirá seu curso bem rapidamente, alimentará as estatísticas de certificação, sem "sacrificar" e "ocupar" muito a estrutura da Universidade.

\section{Segundo Plano de Desenvolvimento Institucional (PDI) - 2008-2012}

Em abril de 2009, a Universidade aprovou o segundo PDI (UFF, 2009), referente ao quadriênio 2008-2012, explicitando na sua introdução um suposto compromisso com o art. 207 da Constituição Federal, que versa sobre o respeito ao princípio da indissociabilidade entre ensino, pesquisa e extensão e da autonomia didático-científica, administrativa, financeira e patrimonial (UFF, 2009). 
O PDI 2008-2012 (UFF, 2009) adotou como pontos norteadores as diretrizes anteriormente apresentadas do PDI 2003-2007 e do próprio Decreto do Reuni, mas surgiu como uma proposta um pouco mais sofisticada em relação ao primeiro Plano. Aponta para a necessidade de expansão do número de vagas e uma "melhoria qualitativa dos cursos" (UFF, 2009, p. 9), além de defender a criação de condiçôes para a ampliação do acesso e da permanência na Educação Superior, um melhor aproveitamento da estrutura física e dos recursos humanos existentes na UFF.

Exalta o Reuni todo o tempo, e aponta o Decreto como o responsável por criar condiçóes ideais para a UFF que poderão:

[...] ampliar, aprofundar e conferir sustentabilidade às açôes de seu PDI, melhorando a qualidade da expansão já existente e realizando investimentos planejados em infra-estrutura e pessoal que estabeleçam uma base sólida para o desenvolvimento da Universidade para além dos 5 anos de duração previstos no Reuni. (UFF, 2009, p. 10).

Defende a reestruturação curricular, a fim de diminuir a retenção e a evasão estudantis, e a criação de novos cursos e turnos noturnos, sempre nos moldes estabelecidos pelo Reuni.

O estímulo ao uso das novas tecnologias da informação através de cursos semipresenciais e da EAD também está presente neste PDI, como açôes estratégicas importantes para a UFF alcançar suas metas. Mais uma vez, o documento estimula a criaçáo de cursos interdisciplinares e apregoa o apoio a "pesquisas inovadoras" que atendam aos interesses da "sociedade" (UFF, 2009). Incentiva a criação de cursos de formação continuada para professores da rede pública e sugere a reestruturação dos cursos de mestrado e doutorado que náo atingem as metas estabelecidas pelas avaliaçóes da Capes.

Com relação à política de pessoal docente da UFF, o PDI aponta para a necessidade da realizaçáo de concursos públicos para o Magistério Superior apenas para as classes de Titular e Adjunto, sempre exigindo o título de doutorado, exceto quando a área de concentração do certame não conte com número suficiente de doutores no País.

A assistência estudantil também assume papel relevante na política universitária da UFF, conforme já vinha se desenvolvendo nos documentos 
anteriores. O PDI 2008-2012 (UFF, 2009) determina que a Universidade deverá facilitar o transporte dos alunos, construir alojamento estudantil e ampliar os programas de bolsas de assistência social aos alunos, além de fortalecer o Núcleo Sensibiliza UFF para atender alunos com necessidades especiais.

Por fim, o PDI 2008-2012 (UFF, 2009) aponta para a necessidade de capacitação permanente da força de trabalho, nos parâmetros defendidos pelo $\mathrm{BM}$, defende a avaliação permanente dos docentes e dos técnico-administrativos, aprofundando uma cultura de educaçáo continuada ao longo da vida produtiva e de avaliação meritocrática.

As metas estabelecidas pelo Acordo de Metas do Reuni (ADUFF, 2008), assinado pela UFF com o MEC, já estavam em curso quando da elaboração do segundo PDI, como objetivos a serem alcançados no quadriênio 2008-2012, porém, para melhor compreendê-las, faz-se necessária uma análise específica do Acordo de Metas.

\section{Termo de Acordo de Metas - 2008}

O Termo de Acordo de Metas (BRASIL, 2008), pactuado entre a UFF e o MEC em 14 de abril de 2008, é um instrumento de contrato de gestão, no qual a Universidade se compromete a cumprir determinadas metas estipuladas pelo Decreto Reuni, em troca de recursos financeiros para implantaçáo de projetos de expansão e reestruturação, tanto de ordem física quanto de pessoal, principalmente nas unidades do interior.

É onde mais claramente se pode verificar a aderência ao modelo de educação terciária, difundido pelos organismos internacionais, como Lima (2009) analisa. Para a autora, o Acordo de Metas (BRASIL, 2008) deixa:

[...] evidente [...] que o financiamento indicado pelo governo federal para reestruturação e expansão das universidades federais está condicionado ao cumprimento de metas expressas nos contratos de gestáo, efetivando a conversão destas IES em organizaçôes de ensino, nos termos bancomundialistas (LEHER; BARRETO, 2008), descaracterizando [ainda] o conceito de universidade pautado na indissociabilidade entre ensino, pesquisa e extensão. (LIMA, 2009, p. 12). 
Neste Termo de Metas (BRASIL, 2008), a UFF se compromete, primeiramente até 2012, e finalmente em 2017, a atingir indicadores referentes ao aumento no número de matrículas, aumento da relação professor/aluno e aumento da taxa de alunos concluintes. A Tabela 1 (conforme subcláusula $1^{\underline{a}} \mathrm{da}$ cláusula $7^{\mathrm{a}}$ do Acordo) sintetiza o que se estava acordando, ao longo dos anos: Tabela 1 - de Indicadores e Dados Globais

\begin{tabular}{|c|c|c|c|c|c|c|c|c|c|}
\hline \multicolumn{10}{|c|}{ UFF - UNIVERSIDADE FEDERAL FLUMINENSE } \\
\hline \multicolumn{3}{|c|}{ Indicadores } & 2007 & 2008 & 2009 & 2010 & 2011 & 2012 & 2017 \\
\hline \multirow{9}{*}{ Graduação } & \multirow{2}{*}{\begin{tabular}{|l|}
$\begin{array}{l}\text { Número de } \\
\text { cursos }\end{array}$ \\
\end{tabular}} & Total & 66 & 77 & 99 & 117 & 122 & 121 & 121 \\
\hline & & \begin{tabular}{|l|} 
Noturno \\
\end{tabular} & 19 & 20 & 38 & 47 & 50 & 49 & 49 \\
\hline & \multirow{2}{*}{$\begin{array}{l}\text { Vagas } \\
\text { anuais }\end{array}$} & Total & 4.818 & 5.428 & 8.008 & 9.388 & 9.958 & 9.958 & 9.958 \\
\hline & & Noturno & 1.140 & 1.315 & 3.093 & 3.745 & 4.045 & 4.045 & 4.045 \\
\hline & \multirow{2}{*}{$\begin{array}{l}\text { Matrículas } \\
\text { projetadas }\end{array}$} & Total & 23.384 & 26.367 & 38.056 & 44.364 & 46.934 & 46.934 & 46.934 \\
\hline & & Noturno & 5.087 & 5.900 & 13.603 & 15.544 & 17.866 & 17.866 & 17.866 \\
\hline & \multirow{2}{*}{\begin{tabular}{|l|} 
Alunos \\
diplomados
\end{tabular}} & Total & 2.730 & 2.900 & 3.098 & 3.341 & 3.972 & 4.354 & 8.962 \\
\hline & & Noturno & 586 & 688 & 789 & 836 & 1.148 & 1.857 & 3.640 \\
\hline & \multicolumn{2}{|c|}{$\begin{array}{l}\text { Taxa de conclusão dos } \\
\text { cursos de graduaçáo (\%) }\end{array}$} & 64 & 68 & 71 & 71 & 87 & 90 & 90 \\
\hline \multirow{4}{*}{$\begin{array}{l}\text { Pós- } \\
\text { Graduação }\end{array}$} & \multirow{2}{*}{$\begin{array}{l}\text { Número de } \\
\text { cursos }\end{array}$} & Mestrado & 39 & 40 & 43 & 44 & 44 & 44 & 44 \\
\hline & & Doutorado & 24 & 26 & 27 & 29 & 29 & 29 & 29 \\
\hline & \multirow{2}{*}{ Matrículas } & Mestrado & 2.044 & 2.077 & 2.188 & 2287 & 2.345 & 2.391 & 2.585 \\
\hline & & Doutorado & 1.010 & 1.044 & 1.119 & 1.199 & 1.271 & 1.322 & 1.484 \\
\hline \multicolumn{3}{|c|}{ Número de Professores Equivalentes } & 3.358 & 3.577 & $3.899,50$ & $4.025,05$ & $4.254,45$ & $4.254,45$ & $4.254,45$ \\
\hline \multicolumn{3}{|c|}{$\begin{array}{l}\text { Número de Professores com } \\
\text { Equivalência DE }\end{array}$} & $2.166,45$ & $2.307,74$ & $2.515,81$ & $2.596,81$ & $2.744,81$ & $2.744,81$ & $2.744,81$ \\
\hline \multicolumn{3}{|c|}{$\begin{array}{l}\text { Deduçáo por integração da } \\
\text { Pós-Graduação }\end{array}$} & 108,32 & 115,39 & 125,79 & 129,84 & 137,24 & 137,24 & 137,24 \\
\hline \multicolumn{3}{|c|}{ Corpo Docente Ajustado } & $2.058,13$ & $2.192,35$ & $2.390,02$ & $2.466,97$ & $2.607,57$ & $2.607,57$ & $2.607,57$ \\
\hline \multicolumn{3}{|c|}{$\begin{array}{l}\text { Relaçáo de alunos de graduaçáo } \\
\text { por professor }\end{array}$} & 11,36 & 12,03 & 15,92 & 17,98 & 18 & 18 & 18 \\
\hline
\end{tabular}

Fonte: Termo de Acordo de Metas UFF-MEC (BRASIL, 2008).

Em linhas bem gerais, a análise dos dados anteriores indica que, até 2011, a UFF teria que realizar um aumento de aproximadamente $101 \%$ no número de matrículas, e este aumento deveria ser de $251 \%$ no período noturno. Até 2017, o número de concluintes deverá ter um acréscimo de $228 \%$, e essa taxa no período noturno deverá alcançar a cifra de $521 \%$. 
Pode-se observar, ainda, que a expansão das matrículas e o aumento no número de concluintes deveriam ocorrer com forte intensificação do trabalho docente, já que a relação de alunos de graduação por professor sofreria um acréscimo de $58 \%$, mesmo considerando as novas contrataçôes.

Com esse agressivo crescimento no número de alunos, aliado a um falso incremento na força de trabalho, o Reuni vai atingindo seus objetivos, que podem ser facilmente identificados na evoluçáo da relação aluno-professor conforme, demonstra tabela 2:

Tabela 2 - Relação Aluno-Professor UFF (2007-2017)

\begin{tabular}{c|c|c|c|c|c|c}
\hline \multicolumn{7}{c}{ Relaçáo de alunos de graduaçáo por professor RAP na UFF pelos } \\
critérios do Reuni \\
\hline $\mathbf{2 0 0 7}$ & $\mathbf{2 0 0 8}$ & $\mathbf{2 0 0 9}$ & $\mathbf{2 0 1 0}$ & $\mathbf{2 0 1 1}$ & $\mathbf{2 0 1 2}$ & $\mathbf{2 0 1 7}$ \\
\hline 11,36 & 12,03 & 15,92 & 17,98 & 18 & 18 & 18,28 \\
\hline
\end{tabular}

Fonte: Gregório (2011).

Se considerarmos apenas os anos do Reuni, temos a seguinte evoluçáo/ involução dos indicadores da UFF, o que nos demonstra que a evolução do número de matrículas de graduação é bem superior ao incremento no quadro de pessoal docente da universidade.

Tabela 3 - Indicadores UFF período Reuni (2007-2010)

\begin{tabular}{c|c|c|c|c}
\hline \multicolumn{4}{c}{ Evoluçáo/involução de indicadores da uff no período 2007-2010 } \\
\hline & Docentes & $\begin{array}{c}\text { Vagas } \\
\text { discentes }\end{array}$ & $\begin{array}{c}\text { Matrículas } \\
\text { graduaçáo }\end{array}$ & Cursos \\
\hline 2007 & 2.209 & 4.898 & 23.652 & 120 \\
\hline 2010 & 2.920 & 8.170 & 36.103 & 161 \\
\hline$\Delta 2007-2010$ & 711 & 3.272 & 12.451 & 41 \\
\hline$\Delta \%$ & $32,18 \%$ & $66,80 \%$ & $52,64 \%$ & $34,16 \%$ \\
\hline
\end{tabular}

Fonte: Gregório (2011).

Entretanto, esses números se agravam quando apresentamos o déficit anterior (1995-2005): 
Tabela 4 - Indicadores UFF período (1995-2010)

\begin{tabular}{c|c|c|c|c}
\hline \multicolumn{5}{c}{ Evoluçáo/involuçáo de indicadores da uff no período 1995-2010 } \\
\hline & Docentes & Vagas discentes & $\begin{array}{c}\text { Matrículas } \\
\text { graduaçáo }\end{array}$ & Cursos \\
\hline 1995 & 2.572 & 3.440 & 15.967 & 45 \\
\hline 2010 & 2.920 & 8.170 & 36.103 & 88 \\
\hline$\Delta 1995-2010$ & 348 & 4.730 & 20.136 & 39 \\
\hline$\Delta \%$ & $13,53 \%$ & $137,50 \%$ & $126,11 \%$ & $95,55 \%$ \\
\hline
\end{tabular}

Fonte: Gregório (2011).

Por fim, deve-se recordar que, pelo "Acordo", o não-cumprimento destas metas implicaria a interrupção da transferência de recursos.

\section{Considerações finais}

A pesquisa feita em documentos oficiais de algumas universidades federais no País, particularmente a investigação levada a cabo na Universidade Federal Fluminense, tem indicado que o processo de contrarreforma da Educação Superior está sendo operacionalizado de forma compactuada, tendo as universidades assumido o importante papel de articuladoras deste processo. Isto porque as universidades têm processado as diretrizes da política neoliberal para a Educação Superior, difundidas pelo governo, antes mesmo de sua adesão mais recente ao Reuni. Na verdade, a adesão a este Programa intensificou e legitimou as açóes de universidades já alinhadas às diretrizes neoliberais, bem como contribuiu para a operacionalização da noção de educação terciária difundida pelo BM, com contornos mais ampliados.

No caso da UFF, que tivemos a oportunidade de apreciar mais detidamente, também concluímos que a adesão ao Reuni é mais uma das ações que a Universidade está operacionalizando no contexto de sua inserção na contrarreforma da Educação Superior que, sob uma dinâmica de continuidades e novidades, retoma a diretriz de diversificação das IES e dos cursos e a adesão ao Programa governamental de expansão.

Grande parte das diretrizes trazidas pelo Reuni refletem e legitimam, na verdade, muitas açôes em curso na Universidade. Grosso modo, vale reproduzir o que frequentemente se escuta no cotidiano da instituição: "O Reuni é somente a cereja do bolo". 


\section{Notas}

1 A referida pesquisa é desenvolvida junto ao Grupo de Estudos e Pesquisas em Educação Superior (Gepes/UFF) e ao Projeto Integrado da Rede Universitas/Br do GT11 da Associação Nacional de Pós-Graduação e Pesquisa em Educação (ANPEd).

2 Ao contrário da noçẫo de reforma, que indica a ampliação de direitos, ainda que nos marcos da ordem burguesa, a contrarreforma caracteriza um conjunto de açôes que elimina ou reduz direitos historicamente conquistados.

3 Ciclo Básico é o período inicial do Curso Superior, com duração média de dois anos ou quatro semestres. Essa denominaçấo advém do fato de as disciplinas que compóem o Ciclo Básico serem comuns a todos os cursos de graduação da área.

\section{REFERÊNCIAS}

BANCO MUNDIAL. Construir sociedades de conocimiento: nuevos desafíos para la educación terciaria. Washington, DC: World Bank, 2003. Disponível em: <http://siteresources.worldbank.org/TERTIARYEDUCATION/ Resources/Documents/Constructing-Knowledge-Societies/CKS-spanish. pdf>. Acesso em: 15 dez. 2009.

BRASIL. Presidência da República. Decreto no 6.096, de 24 de abril de 2007. Institui o programa de apoio a planos de reestruturação e expansão das Universidades Federais - Reuni. Diário Oficial da União, Brasília, DF, 25 abr. 2007. Disponível em: <http://www.dee.ufcg.edu.br/dee/arquivos/ Decreto.6096.de.24.04.2007.pdf>. Acesso em: 17 ago. 2008. Acesso em: 12 dez. 2009.

BRASIL. Ministério da Educação. Secretária da Educação Superior. Acordo de Metas do Reuni n. 044, de março de 2008. Celebram entre si a União representada pelo Ministério da Educação, por intermédio da Secretária de Educação Superior e Universidade Federal Fluminense, para os fins que especifica o Decreto no 6.096 de 24 de abril de 2007. Diário Oficial da União, Brasília, DF, março de 2008. Disponível em: <http://www.aduff.org. br/especiais/observatorio01b.htm\#miniaturas>. Acesso em: 12 dez. 2009. 
BRASIL. Instituto Nacional de Estudos e Pesquisas Educacionais Anísio Teixeira. Censo da Educação Superior/Resumo Técnico. Brasília: MEC, 2002. Disponível em: <http://portal.inep.gov.br/web/censo-da-educacao-superior/ resumos-tecnicos>. Acesso em: 22 jan. 2012.

BRASIL. Instituto Nacional de Estudos e Pesquisas Educacionais Anísio Teixeira. Censo da Educação Superior/Resumo Técnico. Brasília: MEC, 2010. Disponível em: <http://portal.inep.gov.br/web/censo-da-educacao-superior/ resumos-tecnicos>. Acesso em: 22 jan. 2012.

GREGÓRIO, José Renato Bez. Política de pessoal docente do governo Lula: uma análise do Reuni na UFF e seus desdobramentos. 2011. 269 f. Dissertação (Mestrado em Educação) - Programa de Pós-Graduação em Educação, Universidade Federal Fluminense, Niterói, 2011.

LIMA, Kátia Regina de Souza. Contra-reforma na Educação Superior: de FHC a Lula. São Paulo: Xamã, 2007.

LIMA, Kátia Regina de Souza. Contrarreforma da educação nas universidades federais: o Reuni na UFF. Universidade e Sociedade, Andes-SN, Brasília, n. 44, p. 147-157, jul. 2009.

MATTOS, Marcelo Badaró. Reorganizando em meio ao refluxo: ensaios de intervenção sobre a classe trabalhadora no Brasil atual. Rio de Janeiro: Vício de Leitura, 2009.

NEVES, Lucia Maria Wanderley. O empresariamento da educação: novos contornos do Ensino Superior no Brasil dos anos 1990. São Paulo: Xamã, 2002.

UNIVERSIDADE FEDERAL DE MATO GROSSO DO SUL. Plano de Desenvolvimento Institucional 2005-2009. Campo Grande, MS, dez. 2005. Disponível em: <http://www.pdi.ufms.br/?section=download\&itemId=39>. Acesso em: 17 fev. 2012.

UNIVERSIDADE FEDERAL DE SÃO PAULO. Plano de Desenvolvimento Institucional. São Paulo, SP, 2005. Disponível em: <http://www.unifesp.br/ reitoria/pdi/final.doc>. Acesso em: 17 fev. 2012.

UNIVERSIDADE FEDERAL DO RIO DE JANEIRO. Proposta de Plano Qüinqüenal de Desenvolvimento. Rio de Janeiro, RJ, mar. 2006. Disponível em: <http://www.ufrj.br/pr/conteudo_pr.php?sigla=PDI>. Acesso em: 17 fev. 2012. 
UNIVERSIDADE FEDERAL FLUMINENSE - UFF. Portaria GAR N. ${ }^{\circ}$ 29.393, de 26/10/2001. Dispóe sobre o Projeto Pedagógico Institucional. Boletim de Serviço da UFF. Niterói, RJ, 26 out. 2001. Disponível em: <http://www.uff.br/uffon/bs/2001/10/161-2001.pdf>. Acesso em: 22 jan. 2012.

UNIVERSIDADE FEDERAL FLUMINENSE. Projeto Pedagógico Institucional-PPI. Niterói: UFF/PROAC, 2002. Disponível em: <http:// www.uff.br/procult/doc/PPI_UFF.pdf>. Acesso em: 15 jul. 2009.

UNIVERSIDADE FEDERAL FLUMINENSE - UFF. Plano de Desenvolvimento Institucional / PDI - 2003-2007. Niterói, RJ, 2004. (mimeo).

UNIVERSIDADE FEDERAL FLUMINENSE - UFF. Projeto de adesáo da UFF ao Programa Reuni. Niterói, RJ: UFF/Proac, 2007. (mimeo).

UNIVERSIDADE FEDERAL FLUMINENSE - UFF. Regulamento dos Cursos de Graduaçâo. Niterói, RJ: UFF/Proac, 2008. Disponível em: <http:// www.prograd.uff.br/novo/sites/default/files/regulamentocep.pdf>. Acesso em: 22 jan. 2012.

UNIVERSIDADE FEDERAL FLUMINENSE - UFF. Plano de Desenvolvimento Institucional 2008-2012. Niterói, RJ, abr. 2009. Disponível em: <http://www.pdi.uff.br/images/images/PDI_no_EMEC_pos_ Comissao_versao_30abr091.pdf>. Acesso em: 19 out. 2009.

UNIVERSIDADE FEDERAL TECNOLÓGICA DO PARANÁ. Plano de Desenvolvimento Institucional 2004-2008. Curitiba, PR, 2006. Disponível em: <http://www.utfpr.edu.br/a-instituicao/documentos-institucionais/ plano-de-desenvolvimento-institucional-1>. Acesso em: 22 jan. 2012. UNESCO. O Ensino Superior no século XXI - visão e açôes - Documento de Trabalho. Paris, outubro de 1998. In: CRUB. Tendências da Educação Superior para o século XXI. Brasília: UNESCO/CRUB, 1999. 


\section{Cuando Reuni incorporó a la Universidad}

\section{Resumen}

Este trabajo analiza cómo las reconfiguraciones recientes de las universidades federales (IFES), en Brasil, han sido procesadas por lo compartido entre el gobierno federal, a través del Ministerio de Educación (MEC), decanos y sectores importantes de estas instituciones. Presenta los resultados de los análisis de los cambios políticos y pedagógicos generados en la primera década de este nuevo siglo, en las universidades en el contexto de la contrarreforma de la educación superior. A través del análisis de los documentos institucionales de las universidades investigadas, en particular los de la Universidad Federal Fluminense (UFF), el artículo señala las directrices que guían estos cambios, y concluye que el reciente Programa de Apoyo para la Reestructuración y Expansión de las Universidades Federales ha cumplido, en gran medida, el papel de la expansión y legitimación de un proceso ya en marcha, incluso antes de su aplicación.

Palabras claves: Políticas de educación. Educación superior. Reforma universitaria.

\section{The Program for the Restructuring and Expansion of Federal Universities in Brazil (Reuni)}

\section{Abstract}

This article analyzes how the recent reconfigurations of federal universities in Brazil have been undertaken by the Ministry of Education (MEC), university deans and important sectors of these institutions. It presents findings from the analysis of political and pedagogical changes undertaken by universities at the beginning of the first decade of this new century, in the context of their insertion in the counterreformation of higher education. Through the analysis of institutional documents from the universities, particularly the Universidade Federal Fluminense (UFF) in Rio de Janeiro State, the study identifies the guidelines for these changes and concludes that the recent Program for Restructuring and Expansion of Federal Universities (Reuni) largely expanded and legitimized an already ongoing process. Keywords: Policy of education. Higher education. University reform. 
José Renato Bez de Gregório

Email: ddpbezz@vm.uff.br

\section{Viviane de Souza Rodrigues}

Email: vivianerodrigues@vm.uff.br

Deise Mancebo

Email: deise.mancebo@gmail.com

Recebido em: 23/5/2012

Versão final recebida em: 5/10/2012

Aprovado em: 13/11/2012 